\title{
Capsule Commentary on Misra-Hebert et al., Financial Incentives and Diabetes Disease Control in Employees: A Retrospective Cohort Analysis
}

\author{
Marc S. Mitchell, PhD and Paul I. Oh, MD, MSc \\ Cardiovascular Prevention and Rehabilitation Program, University Health Network, Toronto Rehabilitation Institute, Toronto, ON, Canada.
}

J Gen Intern Med 31(8):296

DOI: $10.1007 / \mathrm{s} 11606-016-3716-0$

(c) Society of General Internal Medicine 2016

\begin{abstract}
A dearth of randomized trials testing incentives for chronic disease self-management ${ }^{1}$ makes this retrospective analysis of propensity-matched diabetic employees and nonemployees particularly valuable. The authors found that incentives increased wellness program participation amongst employees (7 to $50 \%$ ), although those with poorer glycemic control (HbA1c $>9 \%)$ were less likely to participate. ${ }^{2}$

The authors suggest that more immediate rewards (not delayed insurance reimbursements) may have stimulated greater participation, and suggest that in the future these could take the form of "waived" copayments. The literature, however, suggests that monetary rewards contingent on health behaviors are more effective than subsidies alone. ${ }^{3}$ In addition, more information about the incentive program would have provided greater design insight. For instance, it was not clear how employees were being rewarded, and for what exactly. Did employees receive lump-sum cash payments, or were rewards rolled into paychecks? Did program "participation" mean enrollment only, $50 \%$ attendance? Fuller reporting of incentive program features using published checklists ${ }^{4}$ would have helped identify specific areas for improvement.

At the population level, incentives stimulated a clinically meaningful 0.33-point reduction in $\mathrm{HbA1c}$, though this took 5 years to achieve. We suggest that, in the context of an already engaged patient population with near optimal glycemic control at baseline (7.38\%), larger incentives worth $\$ 5$ to $\$ 10$ per week ( $\$ 260$ to $\$ 520$ per year), that are dispensed more regularly (every 3 or 6 months, not just once a year), and are tied to regular program participation and meeting incremental and agreed-upon $\mathrm{HbAlc}$ targets (not unrealistic standardized targets) may yield larger effects.
\end{abstract}

These design enhancements (and others-chance-based, loss-framed rewards that leverage behavioral economics principles) $)^{5}$ may increase the proportion of employees, especially higher-risk employees, who sign up for and complete wellness programs and reach $\mathrm{HbAlc}$ targets in the future. Making incentives contingent on small-group performance (e.g., all three in your group must meet targets for rewards to be dispensed), rather than just on individual-level achievements, may optimize the intervention as well. While it is effective, there is much room to improve upon the incentive design examined here.

Corresponding Author: Marc S. Mitchell, PhD; Cardiovascular Prevention and Rehabilitation ProgramUniversity Health Network, Toronto Rehabilitation Institute, Toronto, ON, Canada (e-mail: marc.mitchell@uhn.ca).

\section{Compliance with Ethical Standards:}

Conflict of Interest: The authors have no conflict of interest regarding this article.

\section{REFERENCES}

1. Mitchell M, Goodman J, Alter D, Oh P, Leahey TM, Faulkner GE. A feasibility study of financial incentives to increase exercise among Canadian cardiac rehabilitation patients. J Cardiopulm Rehabilil. 2016;36(1):28-32.

2. Misra-Hebert AD, Hu B, Taksler G, Zimmerman R, Rothberg MB. Financial Incentives and Diabetes Disease Control in Employees: A Retrospective Cohort Analysis. J Gen Intern Med. doi: 10.1007/s11606016-3686-2

3. Mitchell MS, Goodman J, Alter D, Oh P, John L, Pakosh M, Faulkner G. Financial incentives for exercise adherence in adults: a systematic review and meta-analysis of randomized controlled trials. Am J Prev Med. 2013;5(45):658-667.

4. Mitchell M, Goodman J, Alter D, Oh P, Faulkner G. Development of the Health Incentive Program Questionnaire (HIP-Q) in a cardiac rehabilitation setting. Transl Behav Med. 2015;5(4):443-459.

5. Patel M, et al. Framing Financial Incentives to Increase Physical Activity Among Overweight and Obese Adults: A Randomized, Controlled Trial. Ann Intern Med. Published online February 2016; doi:10.7326/M15-1635. 